\title{
Original
}

\section{Synaptic Interaction of Brain Natriuretic Peptide-Containing Axons and Vasopressin Neurons in the Rat Supraoptic Nucleus}

\author{
Yasuyuki Tadokoro ${ }^{1)}$, Kiyoshi Matsumoto ${ }^{1)}$, Seiji Shioda ${ }^{2)}$ \\ and Yasumitsu NAKAI ${ }^{2)}$
}

\begin{abstract}
The innervation of vasopressin (VP)-containing neurons by brain natriuretic peptide (BNP)-containing neurons was examined by electron microscopy using a pre-embedding double immunostaining technique based on the consecutive use of silver-gold intensified peroxidase-antiperoxidase complex-3,3'diaminobenzidine (SGI-PAP-DAB) and the traditional PAP-DAB method in the same tissue sections. BNP-like immunoreactive (BNP-LI) nerve fibers and terminals were distributed in the ventral and dorsal parts of the supraoptic nucleus (SON). Ultrastructural observation revealed that BNP-LI terminals that contained immunoreactive granular vesicles (90-120 nm diameter) formed synapse-like contacts with cell bodies and processes of magnocellular neurosecretory neurons in the SON. On observation of double-immunostained sections of the rat hypothalamic SON, BNP-LI terminals were found to make synapselike contacts with VP-like immunoreactive nerve cell bodies and processes. These findings suggest direct synaptic influence of BNP neurons on the secretory activity of VP-containing neurons in the rat hypothalamic SON.
\end{abstract}

Key words: synapses, BNP neurons, vasopressin neurons, rat supraoptic nucleus, immunoelectron microscopy

\section{Introduction}

Various neurotransmitters have been shown to influence the electrical activity of the hypothalamic magnocellular vasopressin (VP) neurons ${ }^{1)}$. It has been demonstrated by physiological studies that intracerebroventricular injection of brain natriuretic peptide (BNP) suppresses the secretion of $\mathrm{VP}^{2)}$ and adrenocorticotropin ${ }^{3)}$, evoked by angiotensin II in conscious rats. Recently, Yamamoto et al. ${ }^{4)}$ showed, by electrophysiology, that BNP inhibits the spontaneous firing activity of neurons in the anteroventral third ventricle (AV3V) and phasic (putative VP) neurons in the SON in rat hypothalamic slice preparations. These results suggest that BNP acts directly on VP-containing neurons in the SON as well as on AV3V neurons of the rat hypothalamus.

It has been demonstrated biochemically that BNP is present in high concentrations in canine and porcin hypothalamus, striatum, pons-medulla oblongata and spinal cord ${ }^{5,6)}$. Immunohistochemical study ${ }^{i)}$ has shown BNP-like immunoreactive (BNP-LI) cell bodies localized in the

1) Department of Neurosurgery, Showa University School of Medicine, 1-5-8 Hatanodai, Shinagawa-ku, Tokyo 142, Japan.

2) Department of Anatomy, Showa University School of Medicine. 
hypothalamus, as well as in the cerebral cortex, brainstem and spinal cord of the rat. BNPLI nerve fibers have been shown to be widely distributed throughout the brain ${ }^{7,8)}$, and especially abundant in the hypothalamus ${ }^{\top}$. In the hypothalamus, many BNP-LI cell bodies are localized in the tuberomammillary nucleus, and BNP-LI fibers are distributed in the SON, paraventricular nucleus and lateral hypothalamusi). In the SON, BNP-LI terminals are concentrated in the area where many VP-containing neurons are distributed ${ }^{\tau}$. However, morphological relations between BNP- and VP-containing neurons in the SON are still unknown.

In the present study we examined the synaptic interactions between BNP- and VP-containing neurons in the rat hypothalamic SON by a pre-embedding double-immunostaining technique based on the consecutive use of silver-gold intensified peroxidase-antiperoxidase complex-3,3'-diaminobenzidine (SGI-PAP-DAB) and the traditional PAP-DAB method, at the electron-microscopic level.

\section{Materials and Methods}

\section{Animals}

Twelve adult male Wistar rats (150-20 g) pretreated with colchicine were used. All animals were injected with colchicine $(80 \mu \mathrm{g} / 100 \mathrm{~g}$ body weight, dissolved in $5 \mu \mathrm{l}$ saline) through a microsyringe stereotaxically placed into the lateral ventricle under sodium pentobarbital anesthesia $(30 \mathrm{mg} / \mathrm{kg}$; intra peritoneum).

\section{Fixation and section preparation}

Two days atfer the colchicine injection, the animals were reanesthetized with sodium pentobarbital and fixed by intracardiac perfusion, first with $100-150 \mathrm{ml}$ of $0.1 \mathrm{M}$ phosphate buffered saline (PBS, pH 7.4), and then $250 \mathrm{ml}$ of a mixture of $4 \%$ paraformaldehyde and $0.4 \%$ glutaraldehyde in $0.05 \mathrm{M}$ phosphate buffer $(\mathrm{pH} 7.2)$ at $4^{\circ} \mathrm{C}$. After fixation, the preoptic areas were dissected out and immersed for $2 \mathrm{~h}$ at $4^{\circ} \mathrm{C}$ in fixative of the same composition except glutaraldehyde. They were then sectioned at $30-40 \mu \mathrm{m}$ on a Vibratome (Oxford Instruments).

\section{Double immunostaining}

The sections were first rinsed in PBS, and placed in $2 \%$ normal goat serum-PBS solution for $40 \mathrm{~min}$ to prevent the non-specific binding of immunoglobulins to exposed tissue components. They were then sequentially incubated with antiserum against VP $(1: 1,000)$ for $24 \mathrm{~h}$ $4^{\circ} \mathrm{C}$, goat anti-rabbit IgG $(1: 100)$ for $1 \mathrm{~h}$ at room temperature and PAP complex $(1: 800)$ for $90 \mathrm{~min}$ at room temperature. After each incubation step, the sections were thoroughly washed with PBS. The immunoreaction to VP was visualized using DAB. Next, after the addition of $10 \%$ thioglycolic acid for $90 \mathrm{~min}$ at room temperature, silver intensification of the VP-LI material was performed according to a previously described method, and the sections were rinsed with sodium acetate $(5 \mathrm{~min} \times 5)$. Thereafter, a phasical developer was applied for $10 \mathrm{~min}$ at room temperature. The phasical developer of Gallyas ${ }^{9)}$ was used to intensify the DAB end product. The sections were then placed in $1 \%$ acetic acid for $5 \mathrm{~min}$ at room temperature, rinsed with $2 \%$ sodium acetate for $10 \mathrm{~min}$, and gold-toned with $0.05 \% \mathrm{HAuCl}_{1}$ for $10 \mathrm{~min}$ at room temperature. Then, they were rinsed first with $2 \%$ sodium acetate for $10 \mathrm{~min}$, and second wtih PBS for $10 \mathrm{~min}$.

Next, the sections were incubated with antiserum against BNP (1:1,000; Peninsula Lab.) for $24 \mathrm{~h}$ at $4^{\circ} \mathrm{C}$, with goat-anti-rabbit $\operatorname{IgG}(1: 100)$ for $1 \mathrm{~h}$, and with PAP complex for $90 \mathrm{~min}$ 
at room temperature. Then, using $\mathrm{DAB}$, the immunoreaction to $\mathrm{BNP}$ was visualized, after which the sections were postfixed in $1 \% \mathrm{OsO}_{4}$ for $1 \mathrm{~h}$ at $4^{\circ} \mathrm{C}$, dehydrated in a series of ethanols, and embedded in a mixture of Epon-Araldite. Ultrathin sections cut on a Porter Blum microtome were counterstained with uranyl acetate and lead citrate and examined with Hitachi HS-9 and H-7000 electron microscopes.

The BNP antiserum (Lot No. 015647-1) was obtained from Peninsula Laboratories, Inc., U.S.A., and vasopressin antiserum (Lot No. 8416016) was obtained from Immuno Nuclear Corp., U.S.A.

For the control, tissue sections were incubated with antiserum preabsorbed with homologus antigens $(10 \mu \mathrm{g} / \mathrm{ml}$ diluted antiserum) as the primary antiserum.

\section{Results}

\section{Light microscopy}

In the sections singly immunostained by the PAP-DAB method with anti-VP antiserum, several VP-LI cell bodies were found in the SON of the rat, which were especially abundant in the ventral part (Fig. 1a). VP-LI fibers, including axons and dendrites, were distributed in both the dorsal and ventral parts. In the sections stained by the SGI-PAP-DAB method using anti-BNP antiserum, BNP-LI nerve fibers were stained black by the SGI-DAB end products. Many black-colored BNP-LI axons were observed in the ventral and dorsal parts of the SON, but no BNP-LI cell bodies were found in the SON (Fig. 1b).

In the sections doubly-immunostained by SGI-PAP-DAB with BNP antiserum, and the PAP-DAB method with VP antiserum, black-colored BNP-LI terminals were found surrounding the non-intensified, gray-colored VP-LI cell bodies which were visible as brown-colored bodies in the tissue preparations under the light microscope (Fig. $1 \mathrm{c}$ ).

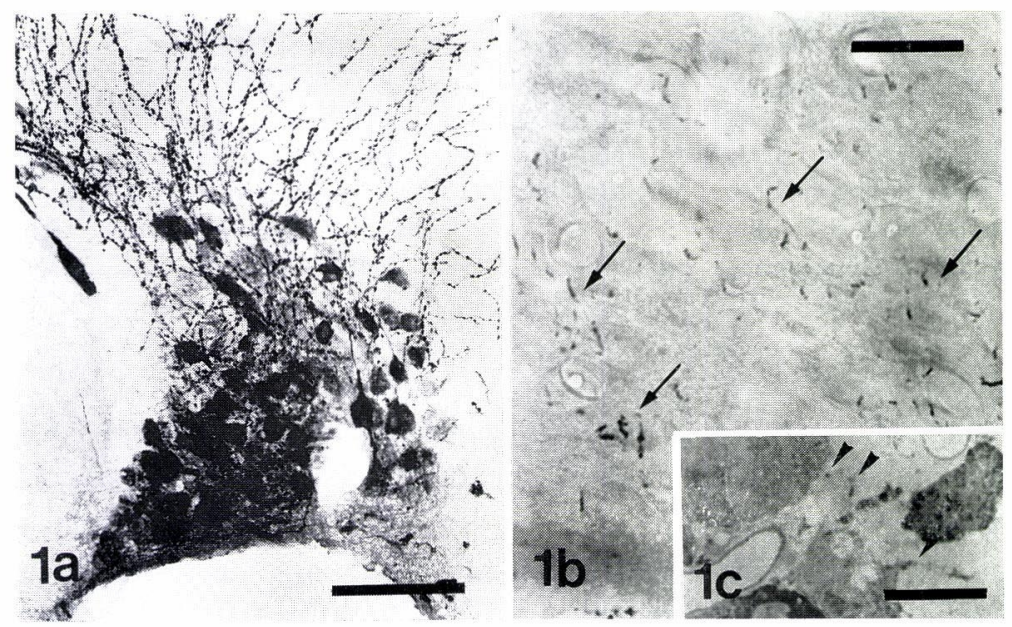

Fig. 1a-c. Light microscopy in the rat SON.

(a): Immunostained VP-LI cell bodies and fibers, including axons and dendrites distributed in both SON dorsal and ventral parts. $\mathrm{Bar}=100 \mu \mathrm{m}$. (b): BNP-LI fibers and terminas labeled by SGI-PAP-DAB (arrows) but no BNP-LI cell body. Bar $=10 \mu \mathrm{m}$. (c): Some terminals (arrowheads) are in direct contact with magnocellular neurons. $\mathrm{Bar}=10 \mu \mathrm{m}$. 


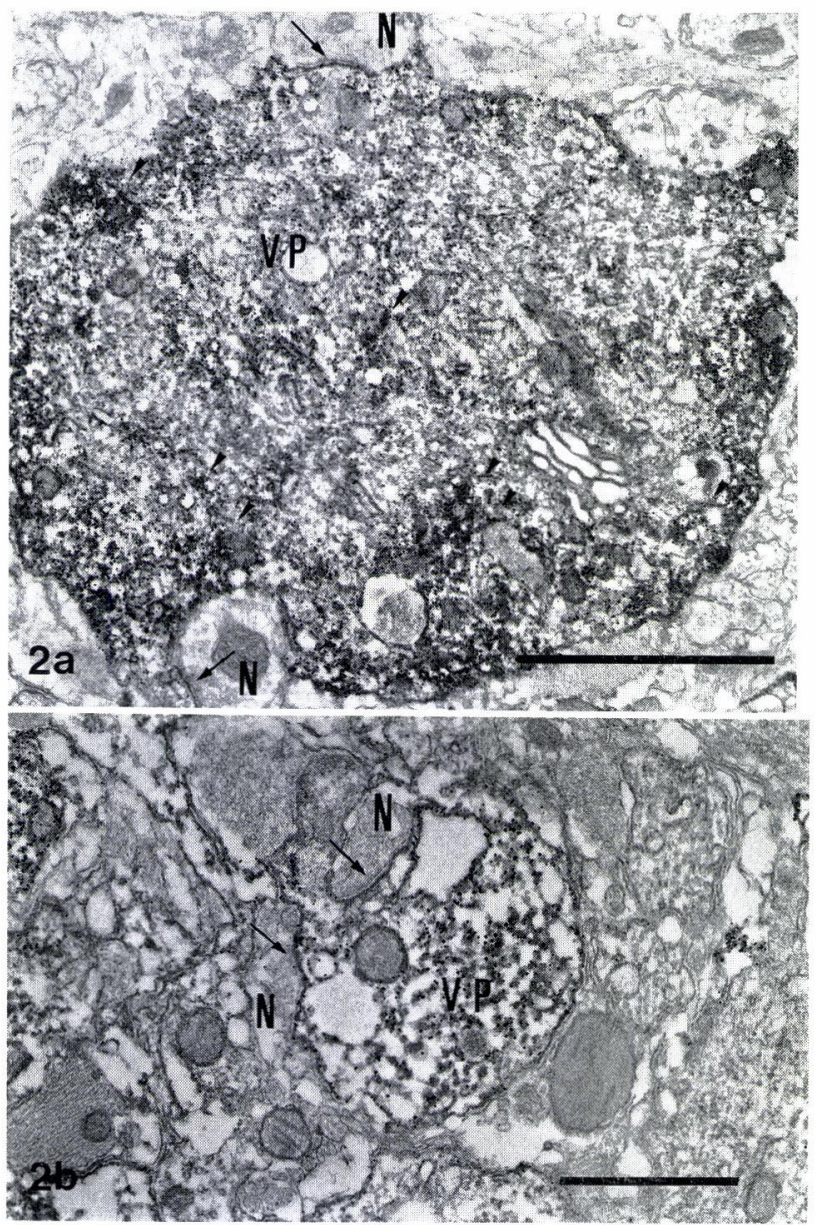

Fig. 2. Electron microscopy in the rat SON.

(a): VP-LI cell body stained by SGI-PAP-DAB (VP). Note the intense electron density of the silver-gold intensified chromogen on VP-LI granules (arrowheads). Three unknown immunonegative terminals $(\mathrm{N})$ make synaptic contacts with the cell body (arrows). Bar $=2 \mu \mathrm{m}$. (b): Two unknown immunonegative terminals (N) make synaptic contact (arrow) with VP-LI process (VP). Bar $=1 \mu \mathrm{m}$.

\section{Electron microscopy}

In the VP single-immunolabeled sections, immunostained by the SGI-PAP-DAB method, the VP-like immunoreaction products were identified by the presence of gold particles substituted for the silver grains and the electron-dense DAB reaction products. These gold particles in the VP-LI neurons appeared mainly in the large dense neurosecretory granules (150-200 nm diameter), and occasionally on the external surfaces of the mitochondria and throughout the cytoplasmic matrices of the perikarya and processes. The nucleus, the Golgi apparatus, the endoplasmic reticulums and the mitochondria were almost free of gold particles (Fig. 2a, b). Immunonegative axon terminals were found to make synaptic contact with VP-LI cell bodies and processes (Fig. 2a, b). Some VP-LI neurons received multiple synaptic inputs on their cell bodies and processes (Fig. 2a, b). 


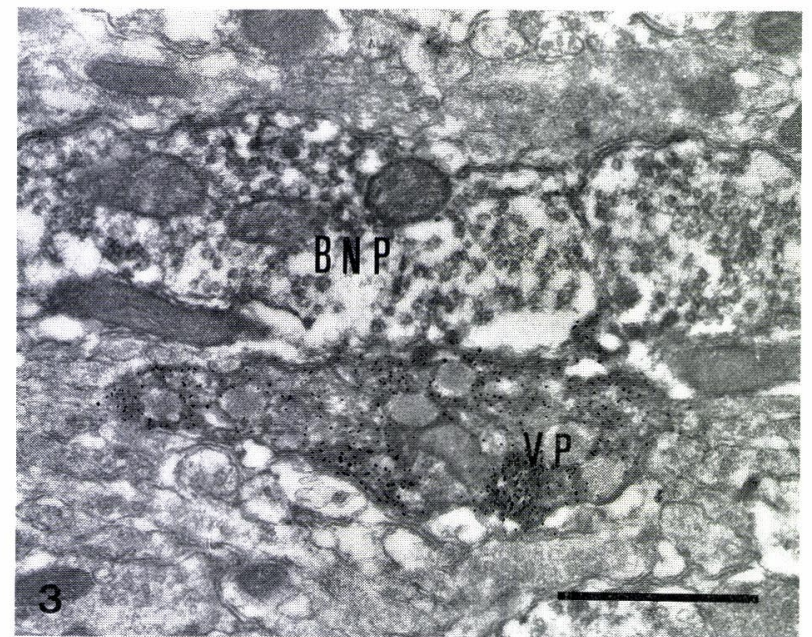

Fig. 3. BNP-LI axon terminals (BNP) indirect contact with VP-LI process (VP). Bar= $0.5 \mu \mathrm{m}$.

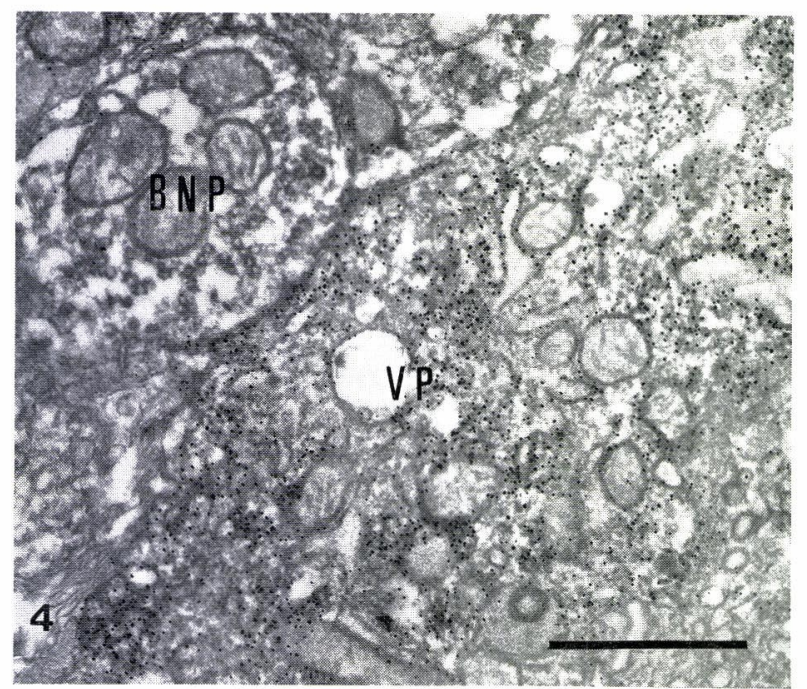

Fig. 4. BNP-LI axon terminals (BNP) making synapse-like contact with VP-LI cell body (VP). $B a r=0.5 \mu \mathrm{m}$.

In the double-immunolabeled sections, immunostained by the SGI-PAP-DAB method with VP antiserum, and by the PAP-DAB method with BNP antiserum, BNP-LI neurons which were labeled simply by the presence of electron-dense DAB reaction products were easily distinguished from the VP-LI neurons labeled with gold particles, as described above. The DAB reaction products in the BNP-LI neurons appeared mainly in the dense granules (90-120 nm diameter) but not in the small clear synaptic vesicles (30-50 nm diameter) (Figs. $3,4,5)$. In these sections, BNP-LI axon terminals were found in direct contact with VP-LI cell bodies and processes (Fig. 3). Occasionally, BNP-LI axon terminals were found to make synaptic contact with VP-LI cell bodies (Fig. 4) and processes (Fig. 5a, b). 


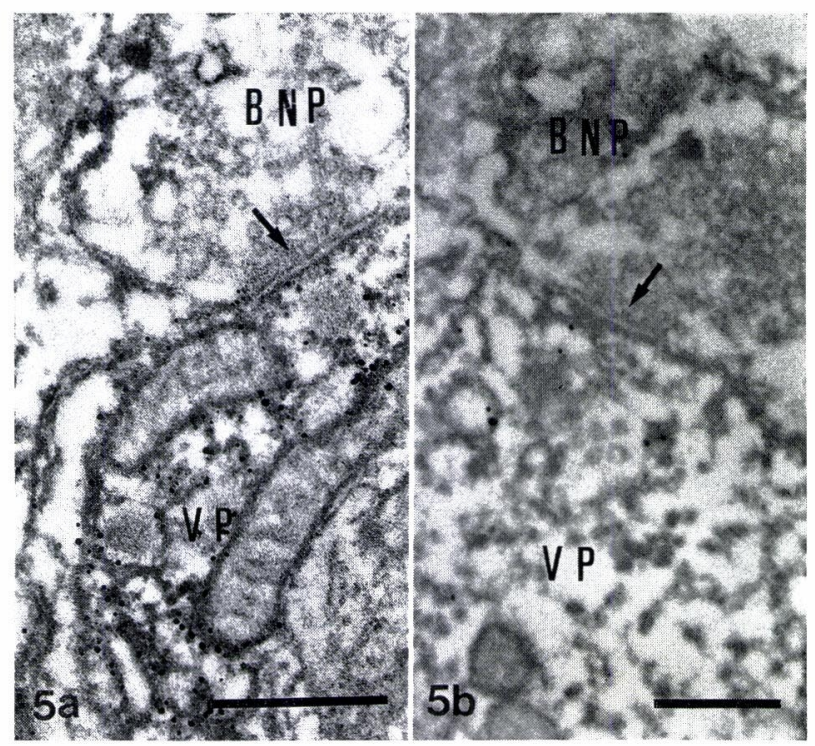

Fig. 5a, b. BNP-LI axon terminal (BNP) making synapse-like contacts (arrow) with VP-LI processes (VP).

(a) : $\operatorname{Bar}=0.5 \mu \mathrm{m}$. (b) : $\operatorname{Bar}=0.2 \mu \mathrm{m}$.

Table 1. Synaptic input of BNP-LI terminals to VP-LI neurons in the rat SON.

\begin{tabular}{lcc} 
& $\begin{array}{c}\text { VP-LI cell bodies } \\
(\mathrm{n}=313)\end{array}$ & $\begin{array}{c}\text { VP-LI processes } \\
(\mathrm{n}=478)\end{array}$ \\
\hline Immunonegative terminals & $86.9 \%$ & $87.0 \%$ \\
BNP-LI terminals & $13.1 \%$ & $13.0 \%$
\end{tabular}

In the present study, 791 synapses were observed to innervate VP-LI neurons in the SON. Of these synapses, 313 were axosomatic and 487 were axo-dendritic. About $13 \%$ of the axon terminals that made synaptic contact with VP-LI neurons were BNP-like immunoreactive (Table 1). At these synapses, small, clear immunonegative vesicles were located in the BNP-LI axon terminals adjacent to the synapse, but granular immunoreactive vesicles were generally located farther from the synaptic active zone (Fig. 5a, b). A few PAP-DAB reaction products were found on the inner surfaces of the presynaptic plasma membranes and in the cytoplasmic matrix. Although both asymmetrical (Gray I) and symmetrical (Gray II) types of synapses were found between BNP-LI axon terminals and VP-LI neurons, they could not be as clearly differentiated as either the asymmetrical or symmetrical types.

\section{Discussion}

BNP, a novel peptide consisting of 26 amino-acid residues, is a natriuretic peptide isolated from porcine brain ${ }^{10)}$. BNP has a biological potency similar to that of atrial natriuretic peptide (ANP) and their amino-acid sequences are remarkably similar, but BNP synthesis appears to involve different gene systems ${ }^{10)}$.

In certain brain areas both ANP-LI and BNP-LI neurons are found distributed in the 
same area. Immunoreactive nerve fibers for both ANP and BNP have been found in the lateral hypothalamus and in the SON and PVN, although BNP-LI innervation of the VPcontaining cell groups is more intense than ANP-LI input ${ }^{11)}$. It is unlikely that the two peptides are co-localized in the same neuronal elements in these areas. Complementary distribution of these two peptides is evident in the hypothalamus. Most of the ANP-LI cell bodies are found in the anteroventral periventricular nucleus, but these lack BNP-LI cell bodies $^{i)}$. In contrast, the tuberomammillary nucleus, which has virtually no ANP-LI cell bodies $^{12)}$, centains several BNP-LI cell bodies ${ }^{i)}$. Electron microscopic immunocytochemistry has shown ANP-LI axon terminals making synaptic inputs to VP-LI neurons in the parvocellular part of the $\mathrm{PVN}^{13)}$. Electrophysiological studies have indicated that ANP inhibits the activity of AV3V neurons and putative parvccellular and magnocellular neurosecretory neurons in the PVN, but not SON neurons ${ }^{1+1.5)}$. It has been reported that iontophoretic application of ANP inhibits activity of physiologically firing neurons in the PVN ${ }^{16)}$, but it is unclear whether the cells are VP neurons or not. Recently, Yamamoto et al. ${ }^{4)}$ re-examined and showed that $10^{-7} \mathrm{M}$ ANP clearly inhibited $29 \%$ of the neurons in the SON. Therefore, it is suggested that VP-LI neurons in the SON may receive synaptic inputs from both BNPLI and ANP-LI neurons.

The present study represents the first revelation of BNPergic synaptic innervation of VPcontaining neurosecretory neurons in the SON by the use a of double labeling method. It has been shown that neurons in the AV3V, and phasic (putative VP) neurons in the SON are inhibited by $\mathrm{BNP}^{4)}$. A neural connection between the AV3V and SON has been electrophysiologically demonstrated ${ }^{1 i)}$. Neuroanatomical studies by use of HRP transport have shown that neurons in the AV3V region project directly to the SON and PVN in the hypothalamus ${ }^{18,19)}$. Recently, Oldfield et al. $^{20)}$ showed, by use of anterograde HRP transport with VP immunocytochemistry, that neurons in the median preoptic nucleus project processes to VP-containing neurons of the SON in sheep. Thus, it may be reasonable to assume that the BNP inhibition of VP release in the posterior pituitary may be due to a combination of direct action of BNP on VP-containing neurons through synapses and an indirect action of BNP through synaptic projeciton from the AV3V to the SON ${ }^{4)}$.

Many BNP-LI cell bodies are found in the dorsal nucleus of the vagus nerve and the nucleus ambiguus in the medulla ${ }^{i)}$. Also BNP-LI neurons are found in the midbrain in the Edinger-Westphal nucleus and ventral tegmental area ${ }^{i)}$. The tuberomamillary nucleus in the hypothalamus contains one of the largest populations of BNP-LI cell bodies in the brain ${ }^{7}$. Köhler et al. ${ }^{21)}$ showed that ascending fibers of the tuberomammillary nucleus project to or through various parts of the neocortex, hippocampal formation, amygdala, basal ganglia, thalamus, superior colliculus hypothalamus including the PVN, and the cerebellum. The sources of the BNPergic input to the magnocellular VP-containing neurons in the SON are still unknown.

An autoradiographic study has demonstrated BNP and ANP binding sites highly localized in brain regions such as the subfornical organ, area postrema, choroid plexus, and arachnoid mater ${ }^{22}$. A moderate degree of binding to the median preoptic nucleus, SON, and PVN, and to the ventricular lining was also noted ${ }^{22)}$. The distribution of BNP binding sites, as revealed by autoradiography, resembles that of ANP binding sites ${ }^{23)}$. Recent reports have demonstrated that a group of natriuretic peptides has three types of receptors, ANP-A, ANP-B, and ANP-C ${ }^{24)}$. It is suggested that in the AV3V, the actions of BNP and ANP may 
be mediated through the ANP-A receptors ${ }^{4)}$. In the SON, there was a difference between the effects of BNP and ANP on phasic neurons, suggesting different proportions of the different receptor subtypes of the natriuretic peptides in the $\mathrm{SON}^{4)}$. It has been demonstrated physiologically that BNP suppresses water intake ${ }^{3)}$, salt appetite:) and pressor response ${ }^{25)}$. These results may indicate that BNP, in conjunction with or in addition to ANP, could function physiologically in the control of water intake and blood pressure through hypothalamic VP neurons.

The present study provided ultrastructural evidence to suggest direct interactions between BNP- and VP-containing neurons in the rat SON through axo-somatic and/or axo-dendritic synapses.

\section{References}

1) Poulain DA: Electrophysiology of the afferent input to oxytocin- and vasopressin-secreting neurons. Facts and problems. Prog Brain Res, 60: 39-52 (1983)

2) Yamada $T$, Nakao $K$, Itoh $H$, Shirakami G, Kangawa $K$, Minamino $N$, Matsuo $H$ and Imura $H$ : Intracerebroventricular injection of brain natriuretic peptide inhibits vasopressin secretion in conscious rats. Neurosci Lett, 95: 223-228 (1988)

3) Itoh $H$, Nakao K, Yamada $T$, Shirakami G, Kangawa $K$, Minamino N, Matsuo $H$ and Imura $H$ : Antidipsogenic action of a novel peptide, 'brain natriuretic peptide', in rats. Eur J Pharmacol, 150: 193-196 (1988)

4) Yamamoto $\mathrm{S}$, Inenaga $\mathrm{K}$ and Yamashita $\mathrm{H}$ : Inhibition by brain natriuretic peptide of vasopressin neurons in the supraoptic nucleus and neurons in the region of the anteroventral third ventricle in rat hypothalamic slice preparations. J Neuroendocrinol, 3: 85-89 (1991)

5) Ueda S, Minamino N, Sudoh T, Kangawa K and Matsuo M: Regional distribution of immunoreactive brain natriuretic peptide in porcine brain and spinal cord. Biochem Biophys Res Commun, 155: 733-739 (1988)

6) Itoh H, Nakao K, Saitoh Y, Yamada T, Shirakami G, Mukoyama M, Arai H, Hosoda K, Suga S, Minamino N, Kangawa $\mathrm{K}$, Matsuo $\mathbf{H}$ and Imura $\mathbf{H}$ : Radioimmunoassay for brain natriuretic peptide (BNP) detection of BNP in canine brain. Biochem Biophys Res Commun, 158: 120-128 (1989)

7) Saper CB, Hurley KM, Moga MM, Holmes HR, Adams SA, Leahy KM and Needleman P: Brain natriuretic peptides: differential localization of a new family of neuropeptides. Neurosci Lett, 96: 29-34 (1989)

8) Kawata M, Hirakawa M, Kumamoto K, Minamino N, Kangawa K, Matsuo H and Sano Y: Brain natriuretic peptide in the porcine spinal cord: an immunohistochemical investigation of its localization and the comparison with atrial natriuretic peptide, substance $P$, calcitonin gene-related peptide, and enkephalin. Neuroscience, 33: 401-410 (1989)

9) Gallyas F: Suppression of argyrophil III reaction by mercapto compounds. (A prerequisite for intensification of certain histochemical reactions by phasical developers). Acta Histochem, 70: 99105 (1982)

10) Sudoh T, Kangawa $\mathrm{K}$, Minamino $\mathbf{N}$ and Matsuo $\mathrm{H}$ : $\mathrm{A}$ new natriuretic peptide in porcine brain. Nature, 332: 78-79 (1988)

11) Standaert DG and Saper CB: Origin of the atriopeptin-like immunoreactive innervation of the paraventricular nucleus of the hypothalamus. J Neurosci, 8: 1940-1950 (1988)

12) Standaert DG, Needleman $P$ and Saper CB: Organization of atriopeptin-like immunoreactive neurons in the cnetral nervous system of the rat. J Comp Neurol, 253: 315-341 (1986)

13) Abe $T$, Matsui $S$, Ochiai $H$ and Nakai $Y$ : Immunoelectron microscopy of neurons containing atrial natriuretic peptide and their innervation of neurons containing vasopressin in the hypothalamic paraventricular nucleus and median eminence of the rat. J Clin Electron Microscopy, 22: 189-198 (1989)

14) Okuya $S$ and Yamashita $H$ : Effects of atrial natriuretic polypeptide on rat hypothalamic neurons in vitro. J Physiol, 389: 717-728 (1987)

15) Hattori $Y$, Kasai $M$, Uesugi $S$, Kawata $M$ and Yamashita $H$ : Atrial natriuretic polypeptide depresses angiotensin II induced excitation of neurons in the rat subfornical organ in vitro. Brain 
Res, 443: 355-359 (1988)

16) Standaert DG, Cechetto DF, Needleman P and Saper CB: Inhibition of the firing of vasopressin neurons by atriopeptin. Nature, 329: 151-153 (1987)

17) Chaudhry MA, Dyball REJ, Honda K and Wright NC: The role of interconnection between supraoptic nucleus and anterior third ventricular region in osmoregulation in the rat. $J$ Physiol, 410: 123-135 (1989)

18) Saper CB and Levisohn D: Afferent connections of the median preopitc nucleus in the rat; anatomical evidence for a cardiovascular integrative mechanism in the anteroventral third ventricular (AV3V) region. Brain Res, 288: 21-31 (1983)

19) Sawchenko PE and Swanson LW: The organization of forebrain afferents to the paraventricular and supraoptic nuclei of the rat. J Comp Neurol, 218: 121-144 (1983)

20) Oldfield BJ, Miselis RR and Mckinley MJ: Median preoptic nucleus projections to vasopressincontaining neuorns of the supraoptic nucleus in sheep. A light and electron microscopic study. Brain Res, 542: 193-200 (1991)

21) Köhler C, Swanson LW, Haglund L and Wu JY: The cytoarchitecture, histochemistry and projections of the tuberomammillary nucleus in the rat. Neuroscience, 16: 85-110 (1985)

22) Brown $\mathbf{J}$ and Czarnecki A: Autoradiographic localization of atrial and brain natriuretic peptide receptors in rat brain. Am J Physiol, 258: 57-63 (1990)

23 ) Torda T, Nazarali AJ and Saavedra JM: Brain natriuretic peptide receptors in the rat peripheral sympathetic ganglio. Biochem Biophys Res Commun, 159: 1032-1038 (1989)

24) Chang M, Lowe DG, Lewis M, Hellmiss R, Chən E and Goeddel DV: Differential activation by atrial and brain natriuretic peptides of two different receptor guanylate cyclases. Nature, 341: 6872 (1989)

25) Shirakami G, Nakao K, Yamada T, Itoh H, Mori K, Kangawa K, Minamino N, Matsuo H and Imura $\mathrm{H}$ : Inhibitory effect of brain natriuretic peptide on central angiotensin II-stimulated pressor response in conscious rats. Neurosci Lett, 91: 77-83 (1988)

[Received February 10, 1992: Accepted February 22, 1992] 